\title{
Paleodiversity of Late Cretaceous Ankylosauria from Mexico and their phylogenetic significance
}

\author{
Héctor E. Rivera-Sylva ${ }^{1}$ Eberhard Frey ${ }^{2} \cdot$ Wolfgang Stinnesbeck $^{3} \cdot$ Gerardo Carbot-Chanona $^{4}$. \\ Iván E. Sanchez-Uribe ${ }^{1} \cdot$ José Rubén Guzmán-Gutiérrez ${ }^{1}$
}

Received: 28 February 2018/ Accepted: 18 May 2018/Published online: 6 June 2018

(C) Akademie der Naturwissenschaften Schweiz (SCNAT) 2018

\begin{abstract}
Isolated bones and osteoderms of ankylosaurian dinosaurs recovered from Late Cretaceous sediments of northern Coahuila, northeastern Mexico, have been identified as remains of nodosaurids. Here, we summarize these discoveries and provide a review on Mexican Ankylosauria from a taxonomic perspective. We also present a new taxon, Acantholipan gonzalezi gen. et sp. nov. from the Pen Formation and provide a phylogenetic analysis integrating the new taxon. A. gonzalezi is the first named ankylosaur from Mexico that adds to the currently rare nodosaurid diversity from southern Laramidia.
\end{abstract}

Keywords Dinosaur $\cdot$ Nodosauridae $\cdot$ Pen Formation · Mexico · Endemism · Laramidia

\begin{tabular}{|c|c|}
\hline \multicolumn{2}{|c|}{ Abbreviations } \\
\hline AMNH & $\begin{array}{l}\text { American Museum of Natural History, New } \\
\text { York }\end{array}$ \\
\hline CEUM & $\begin{array}{l}\text { College of Eastern Utah Prehistoric Museum, } \\
\text { Price }\end{array}$ \\
\hline СРC & $\begin{array}{l}\text { Colección Paleontológica de Coahuila, Museo } \\
\text { del Desierto, Saltillo }\end{array}$ \\
\hline
\end{tabular}

Editorial Handling: D. Marty.

Electronic supplementary material The online version of this article (https://doi.org/10.1007/s13358-018-0153-1) contains supplementary material, which is available to authorized users.

Héctor E. Rivera-Sylva

hrivera@museodeldesierto.org

1 Departamento de Paleontología, Museo del Desierto, Carlos Abedrop Dávila 3745, 25022 Saltillo, Coah., Mexico

2 Geowissenschaftliche Abteilung, Staatliches Museum für Naturkunde Karlsruhe, Erbprinzenstrasse 13, 76133 Karlsruhe, Germany

3 Institut für Geowissenschaften, Universität Heidelberg, Im Neuenheimer Feld 234-236, 69120 Heidelberg, Germany

4 Museo de Paleontología "Eliseo Palacios Aguilera", Dirección de Paleontología, Secretaría del Medio Ambiente e Historia Natural, Calz. de los Hombres Ilustres s/n, 29000 Tuxtla Gutíerrez, Chiapas, Mexico
FHSM Sternberg Museum of Natural History, Hays

$\mathrm{VP}$

INAH Instituto Nacional de Antropología e Historia, Mexico

IVPP Institute of Vertebrate Paleontology and Paleoanthropology, Beijing

MTM Magyar Természettudományi Múzeum, Budapest

MUDE Museo del Desierto, Saltillo

ROM Royal Ontario Museum, Toronto

UMNH Utah Museum of Natural History, Salt Lake City

\section{Introduction}

Ankylosauria represent a clade of thyreophoran (shieldbearing) Ornithischia characterized by flat and wide skulls, whose roofs have been densely decorated with osteoderms. The armored bodies of these obligatory quadrupeds are barrel shaped (Carpenter 2012; Vickaryous et al. 2004). Ankylosauria are divided into two families: Ankylosauridae (Brown, 1908) and Nodosauridae (Marsh, 1890). Ankylosauridae are characterized by short and wide skulls, and tail clubs, amongst other features. Nodosauridae have an angled ischium, a body and tail covered with massive osteoderms often forming spines, and lack a tail club 
(Arbour and Currie 2016). The highest diversity of Nodosauridae is reached during the Late Cretaceous in North America and Europe. Generally, however, Nodosauridae show a wide range of geographic distribution and are reported from Europe, South America, and Antarctica (Arbour and Currie 2016).

Ankylosaurs are characteristic and abundant components of dinosaur assemblages from the Late Cretaceous of western North America (Laramidia). Campanian strata have yielded numerous specimens of nodosaurids and ankylosaurids, mostly from Canada and the United States. In contrast, the record from the southern part of Laramidia is surprisingly scarce (Loewen et al. 2013; Rivera-Sylva and Carpenter 2014). Ankylosaurid remains are extremely rare in the Late Cretaceous of Mexico, contrasting with the relatively richer hadrosaurian assemblages reported from this region (Morris 1981; Gates et al. 2007; Prieto-Márquez and Serrano-Bráñas 2012; Ramírez-Velasco et al. 2012, 2014). Nevertheless, nodosaurid remains have been reported from Mexican strata, although most of these are undiagnostic (Rivera-Sylva et al. 2011a; Martínez-Díaz and Montellano-Ballesteros 2011). Here, we reexamine the material documented from the "El Gallo Formation" (Campanian) of Baja California Norte, the Aguja Formation (Campanian) of Coahuila, and the Pen Formation
(Santonian) of northern Coahuila (Fig. 1; Palomino-Sánchez 2008; Rivera-Sylva et al. 2011a).

\section{Materials and methods}

The material described here includes specimens CPC 272, and CPC 273 housed at MUDE, both comprising incomplete postcranial elements. They were collected under written authorization of INAH through the permits registered in their sections Consejo Nacional de Paleontología (Oficio 401.13-352) and Consejo Nacional de Arqueología (Oficio 401.B(4)19.2013/36/1862).

Photographs were taken with an Olympus E620 SLR camera with a Zuiko $14-42 \mathrm{~mm} \mathrm{1:3.5-5.6}$ zoom and a Zuiko $35 \mathrm{~mm}, 1: 3.5$ macro lens under optimal natural light. The images were exempted from their background with GIMP GNU 2.8.22. No other manipulations were made.

For the cladistic analysis, we used the data matrix provided by Arbour et al. (2016) and the slightly modified data matrix of Arbour and Currie (2016). We added the scoring of Acantholipan gonzalezi and CPC 273 to this matrix using Mesquite 3.40 (Maddison and Maddison 2018). The phylogenetic analysis was conducted in TNT version 1.1 (Goloboff et al. 2008), using the Traditional Search option

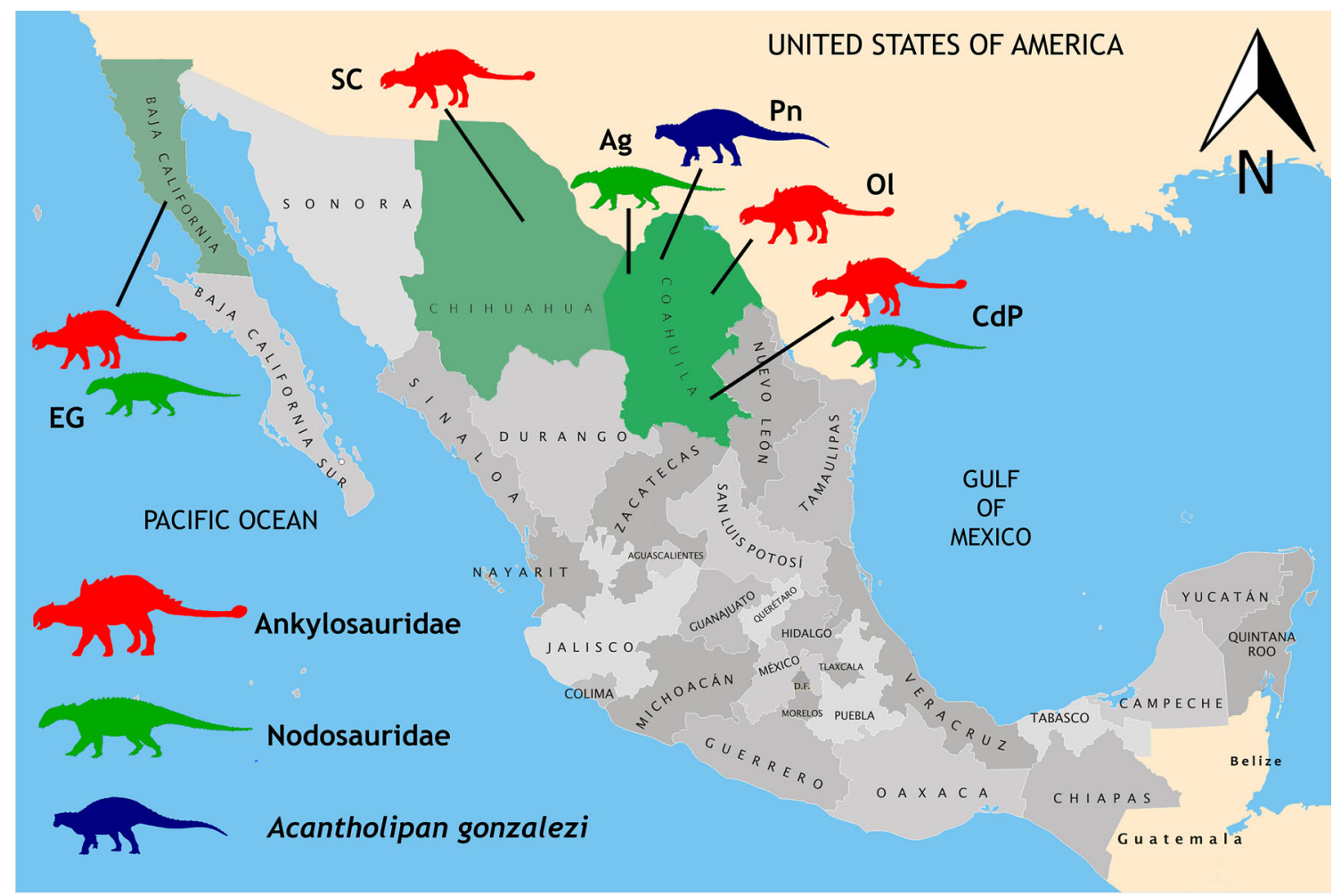

Fig. 1 Geographic location of the ankylosaurid-bearing fossil sites documented here. EG: "El Gallo Formation", Baja California; SC: San Carlos Formation, Chihuahua; Ag: Aguja Formation, Coahuila;
Pn: Pen Formation, Coahuila; Ol: Olmos Formation, Coahuila; CdP: Cerro del Pueblo Formation, Coahuila 
with one random seed and 1000 replicates of Wagner trees, and the tree bisection reconnection (TBR) swapping algorithm, using space for 99,999 trees in memory, and holding ten trees in each replication. All characters were treated as unordered and of equal weight. The strict consensus tree and the majority rule tree (cut 50\%) were calculated from the resulting trees. Bremer supports, consistency index (CI) and retention index (RI) were calculated in TNT using the BREMER.RUN and STATS.RUN scripts, respectively.

\section{Systematic paleontology}

Dinosauria Owen (1842)

Ornithischia Seeley (1887)

Thyreophora Nopcsa (1915)

Ankylosauria Osborn (1923)

Ankylosauridae Brown (1908)

Ankylosauridae indet.

(Fig. 2a-c)

Referred specimen: CPC 1867, osteoderm (Fig. 2a-c)

Horizon and Locality: The material was recovered from the Cerro del Pueblo Formation (Upper Cretaceous; Campanian); LA 14 near Las Águilas, Porvenir de Jalpa, Coahuila, northeast Mexico.

Description: CPC 1867 is the anterior fragment of an osteoderm, which is transversely broken in the middle. The lateral margin is broken, too. The coarsely pitted and wrinkled external face bears a medial blunt longitudinal keel. The ventral surface is smooth and deeply concave. The maximum length of the fragment is $57.1 \mathrm{~mm}$ and the maximum width is $64.1 \mathrm{~mm}$. The maximum thickness is $26.4 \mathrm{~mm}$. The compacta is exceedingly thin, measuring only $2 \mathrm{~mm}$. The large medullar cavity is filled with a foamy irregular spongiosa.
Discussion: Because of the thin-walled compacta, the foamy spongiosa and the deeply concave internal face, the osteoderm is referred to Ankylosauridae (Carpenter, 2004).

Ankylosauridae indet.

Harley J. Garbani identified an osteoderm (LACM 29000) of an ankylosaurid from the "El Gallo Formation" in Baja California (Campanian, Upper Cretaceous) (Morris 1967). The specimen was originally housed in the Los Angeles County Museum, California, USA, and was sent to the Colección Nacional de Paleontología at the Universidad Nacional Autónoma de México (UNAM) in the 1990s. There it was lost (Perrilliat, pers. comm., 2009). However, photos of the lost specimen taken by Tracy Ford in 2000 and shown to one of us (HRS) illustrate half of an internally concave osteoderm that is evidently ankylosaurid.

In his revision of dinosaur material from Mexico, Hernández (1997) mentions the presence of cf. Euoplocephalus as well as Nodosauridae indet. from the "El Gallo Formation". However, the author may simply have followed earlier data given by Morris (1967), because he neither illustrated nor described this material.

Two vertebrae and a metatarsal of an ankylosaurid were reported from the San Carlos Formation (lower Campanian) of Aldama, Chihuahua (Rivera-Sylva et al. 2011a) but were not described because the specimens are housed in a private collection and are not officially available.

Internally concave osteoderms of Ankylosauridae were described by Rivera-Sylva and Espinosa-Chávez (2006) from the Cerro del Pueblo Formation near La Parrita in southern Coahuila. Subsequently, Ramirez-Velasco and Hernández (2014) mention a conical osteoderm with concave internal surface associated with a femur fragment from an unknown locality in Coahuila. Ramirez-Velasco et al. (2014) mention the presence of a metatarsal fragment of Ankylosauria from the Olmos Formation, and a phalanx from the Cerro del Pueblo Formation, both in Coahuila, but
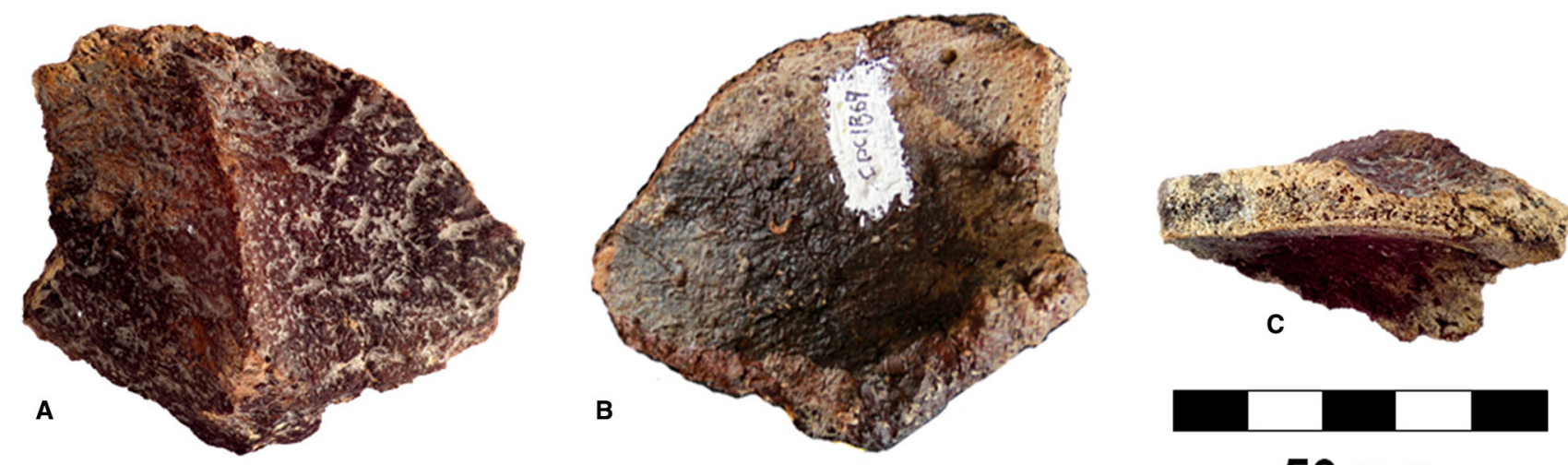

$50 \mathrm{~mm}$

Fig. 2 Ankylosaurid osteoderm (CPC 1867) in: a dorsal, b ventral, and c lateral views. Scale: $50 \mathrm{~mm}$ 
they neither illustrate the specimens nor do they provide measurements or a detailed description of the material, which can therefore not be identified.

An ankylosaur femur from the Olmos Formation near Sabinas, Coahuila, was mentioned by Meyer et al. (2005), but neither properly described nor depicted, because it was housed in a private collection.

Nodosauridae Marsh, 1890

\section{Acantholipan gen. nov.} urn:lsid:zoobank.org:act:BEB89092-0429-49A0-B985FDA4225E62BE

\section{A. gonzalezi sp. nov.}

urn:1sid:zoobank.org:act:4C5F0E44-9C7D-4807-B75B657091475CFA

Fig. $3 \mathrm{a}-\mathrm{g}$

Etymology: Greek $\alpha \gamma \kappa \dot{\alpha} \theta \mathrm{r}$ (acanthus) = spine; and the Spanish contraction of Lépai-Ndé (gray people) lipan, a tribe of Apaches from northern Mexico; gonzalezi = in honor of Arturo H. Gonzalez González, for his outstanding support to Mexican paleontology.

Holotype (Fig. 3a-g):

One dorsal vertebra, one caudal vertebra, one rib fragment, the distal end of a left humerus, a left ulna, the distal end of a left femur, and one distal thoracic osteodermal spine. The holotype of Acantholipan gonzalezi has been previously figured (Rivera-Sylva et al. 2011a: Fig. 3), except for the caudal vertebra, rib and femora that are figured here for the first time (Fig. 3d, f, g). The specimen is housed at the Colección Paleontológica de Coahuila (CPC) at the Museo del Desierto, Saltillo, Coahuila, Mexico, under the collection number CPC 272.

Horizon and locality: The material was recovered from the Pen Formation (Upper Cretaceous, Santonian), at the Los Primos locality, south of the town of San Miguel (RiveraSylva et al. 2011a: Fig. 1), Municipality of Ocampo, Coahuila, Mexico. The exact locality information is on file at the MUDE and is supplied on request.

Diagnosis: Combination of the following characters: (1) ulna with anterolateral process prominent, tapering and truncated proximally (triangular in lateral view); (2) conical and slightly caudally curved lateral thoracic osteoderm with a longitudinal oval cross section and vascular grooves on the lateral face only.

Description: The specimen is from one individual and has previously been documented by Rivera-Sylva et al. (2011a) but had not been formally named as a new species. We refer to this publication for description of the non-diagnostic material. Here, we only reevaluate the ulna and an
4Fig. 3 Acantholipan gonzalezi gen. et sp. n., holotype, CPC 272; left ulna in: a $\mathbf{a}_{1}$ caudal; $\mathbf{a}_{2}$ cranial; $\mathbf{a}_{3}$ lateral; distal thoracic osteodermal spine in: $\mathbf{b}_{\mathbf{1}}$ right lateral; $\mathbf{b}_{\mathbf{2}}$ left lateral; $\mathbf{c}$ dorsal vertebra in cranial view; caudal vertebra in: $\mathbf{d}_{\mathbf{1}}$ cranial and $\mathbf{d}_{\mathbf{2}}$ ventral views; humerus in: $\mathbf{e}_{\mathbf{1}}$ caudal and, $\mathbf{e}_{2}$ ventral views; femur in: $\mathbf{f}_{\mathbf{1}}$ right lateral; and, $\mathbf{f}_{2}$ cranial views; $\mathbf{g}$ rib. Scale: $100 \mathrm{~mm}$

osteodermal spine, being the only diagnostic elements of the present material.

Left ulna (Fig. 3a) - the left ulna of CPC 272 lacks its distal third. The olecranon is prominent, wedge-shaped in lateral view and proximally truncated as in other ankylosaurs (Vickaryous et al. 2004), with a length/height ratio of $1: 1$. In anterior view, the olecranon of CPC 272 forms a broad, inverted right-angled triangle. However, its proximal end is rounded and not pointed as in Sauropelta. The humeral notch at the base of the olecranon is well developed and thus resembles that of Niobrarasaurus and Stegopelta, while the radial notch placed lateral to it is shallow and thus similar to that of other ankylosaurs (Rivera-Sylva et al. 2011a). The anterolateral process is unusually prominent compared with other nodosaurids; it forms an isosceles triangle in outline and is similar in length to the olecranon process.

Osteodermal spine (Fig. 3b) —a long and conical hornlike spine with slight caudal curvature is here interpreted as a posterior thoracic osteoderm (Rivera-Sylva et al. 2011a). In cross section, it is longitudinally oval with a length/ width ratio of 1:3. Vascular grooves are present on its entire lateral face only, thus somewhat resembling a ceratopsian horn-core. CPC 272 is identified as a nodosaurid osteodermal spine because of its conical outline and longitudinal oval cross section.

Comments and comparisons: Nine nodosaurids are presently identified from the Late Cretaceous of North America: Panoplosaurus, Edmontonia, Glyptodontopelta, Niobrarasaurus, Nodosaurus, Silvisaurus, Stegopelta, Aletopelta, and Denversaurus (Carpenter, 2012).

While Acantholipan gonzalezi is of Santonian age, Stegopelta, Silvisaurus, and Nodosaurus are Cenomanian in age, Niobrarasaurus is a Conacian taxon, and Panoplosaurus, Glyptodontopelta, and Denversaurus are Maastrichtian in age (Carpenter 2004, 2012; Burns 2008). Only Edmontonia and Aletopelta are of Campanian age and thus closer with A. gonzalezi from the Pen Formation.

The anterolateral process of de ulna of $A$. gonzalezi differs from that of Edmontonia, Aletopelta, Peloropiltes, Hungarosaurus, and UMNH VP 19473 where the olecranon is half the length of the anterolateral process, while in A. gonzalezi it has a 1:1 ratio in its prominence compared with the olecranon, with its truncated proximal end similar 

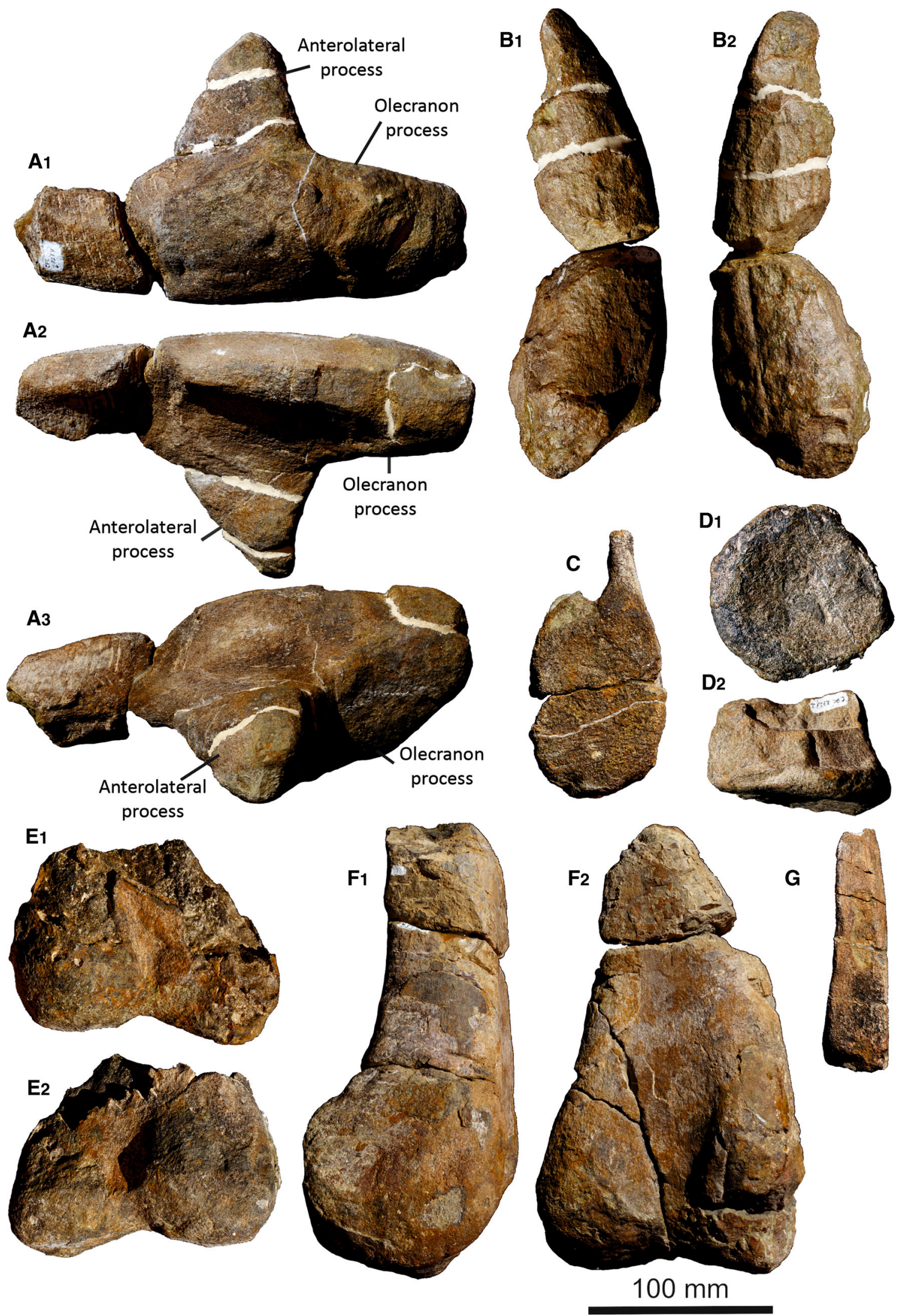


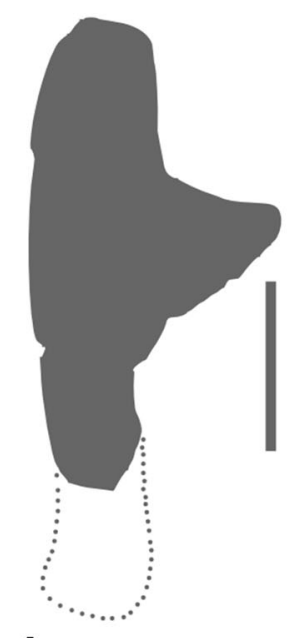

A
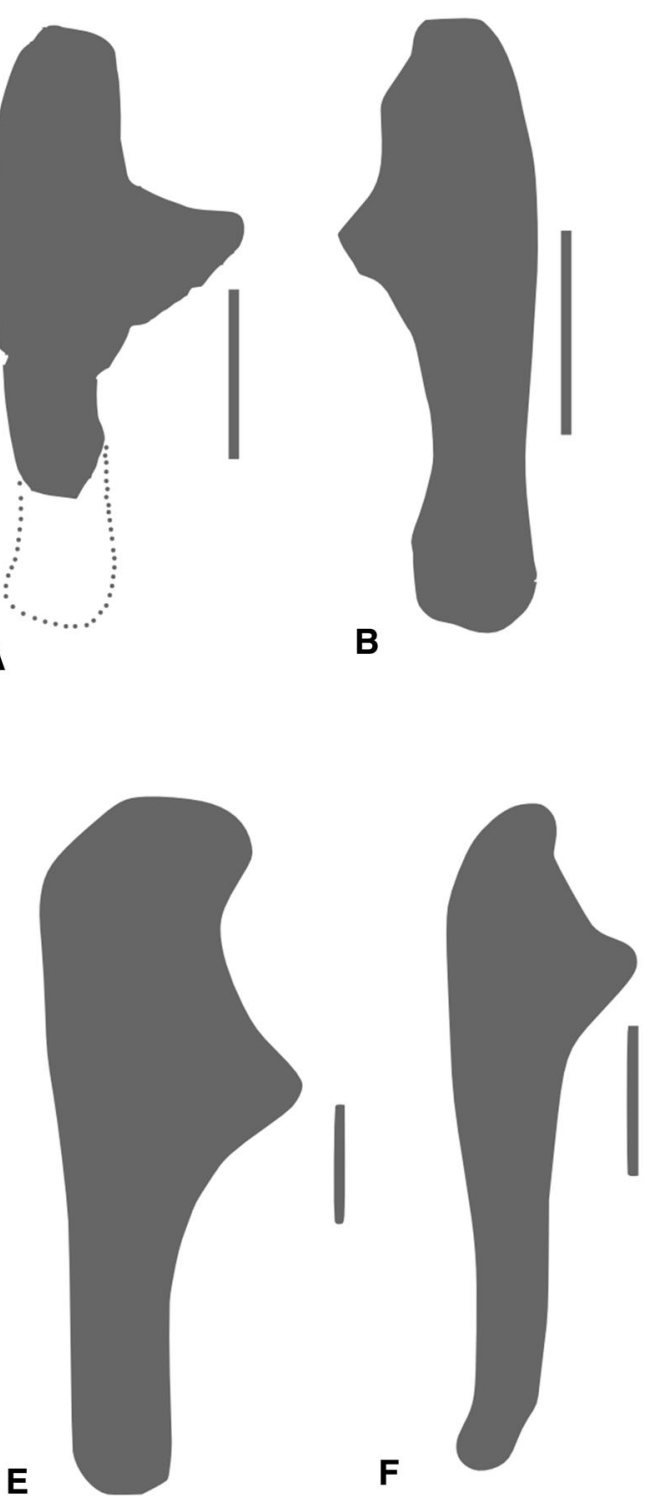

Fig. 4 Comparison of outline drawings of ankylosaur ulnae. a Acantholipan gonzalezi (CPC 272), left ulna in medial view; b Edmontonia rugosidens (ROM 1215), left ulna in anterior view; c UMNH VP 19473, ulna in lateral view; d Liaoningosaurus paradoxus (IVPP V12560), left ulna in medial view; e Peloroplites cedrimontanus (CEUM 11347), right ulna in lateral view; f Hungarosaurus tormai

to Niobrarasaurus coleii (FHSM VP-14855) (Fig. 4) and Stegopelta (Carpenter and Kirkland, 1998).

Ford (2000), Burns (2008) and Burns and Currie (2014) stated that osteoderms of nodosaurids bore diagnostic characters, which is corroborated here in A. gonzalezi. With a width-length ratio of $1: 3$, the osteodermal spine of A. gonzalezi is longer, with respect to its width, than in both Edmontonia and Aletopelta where the ratio is 1:2. In Edmontonia, the thoracic spines are slightly transversely compressed and straight, terminating in a blade (Sternberg
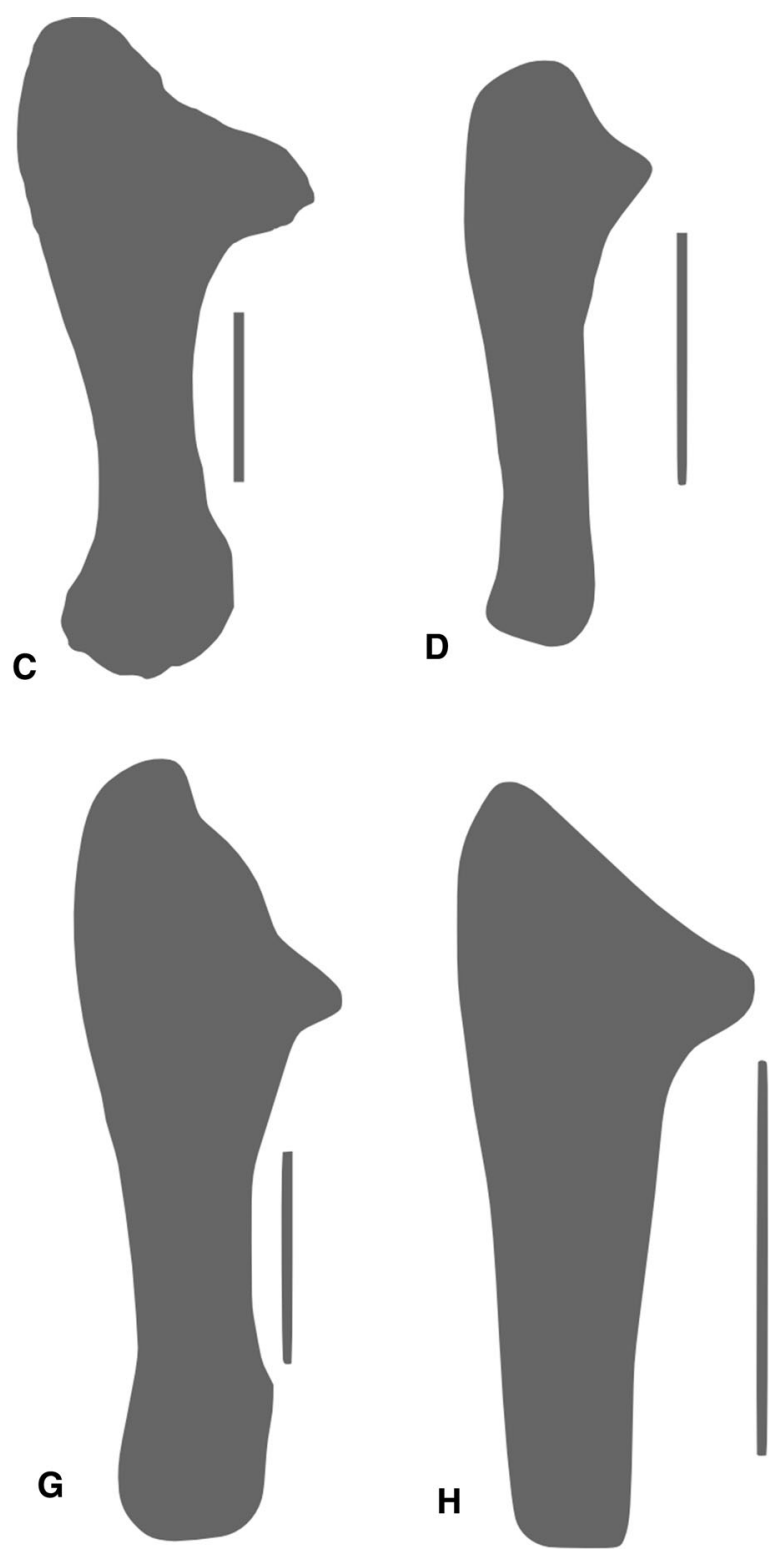

(MTM 2007.25.2), right ulna in lateral view; $\mathbf{g}$ Niobrarasaurus coleii (FHSM VP-14855), right ulna in lateral view; h Minmi sp. (QMF 18101), left ulna in medial view. Scale bars in $\mathbf{a}-\mathbf{c}, \mathbf{e}-\mathbf{h}$ equal $10 \mathrm{~cm}$; scale bar in d equals $1 \mathrm{~cm}$ After: Carpenter et al. (1995), Han et al. (2014); Russell (1940)

1928). In Aletopelta they are much more laterally compressed, being three to four times longer than wide, with blunt anterior and posterior keels (Coombs and Deméré 1996). The osteodermal spine of A. gonzalezi closely resembles those reported for the Santonian Hungarosaurus and Struthiosaurus from Europe (Ösi and Pereda-Suberbiola 2017), but the grooves of $A$. gonzalezi are wider than those reported for the European taxa. The osteodermal spine is interpreted as a distal thoracic spine because it was found near the femur and the caudal vertebra. 


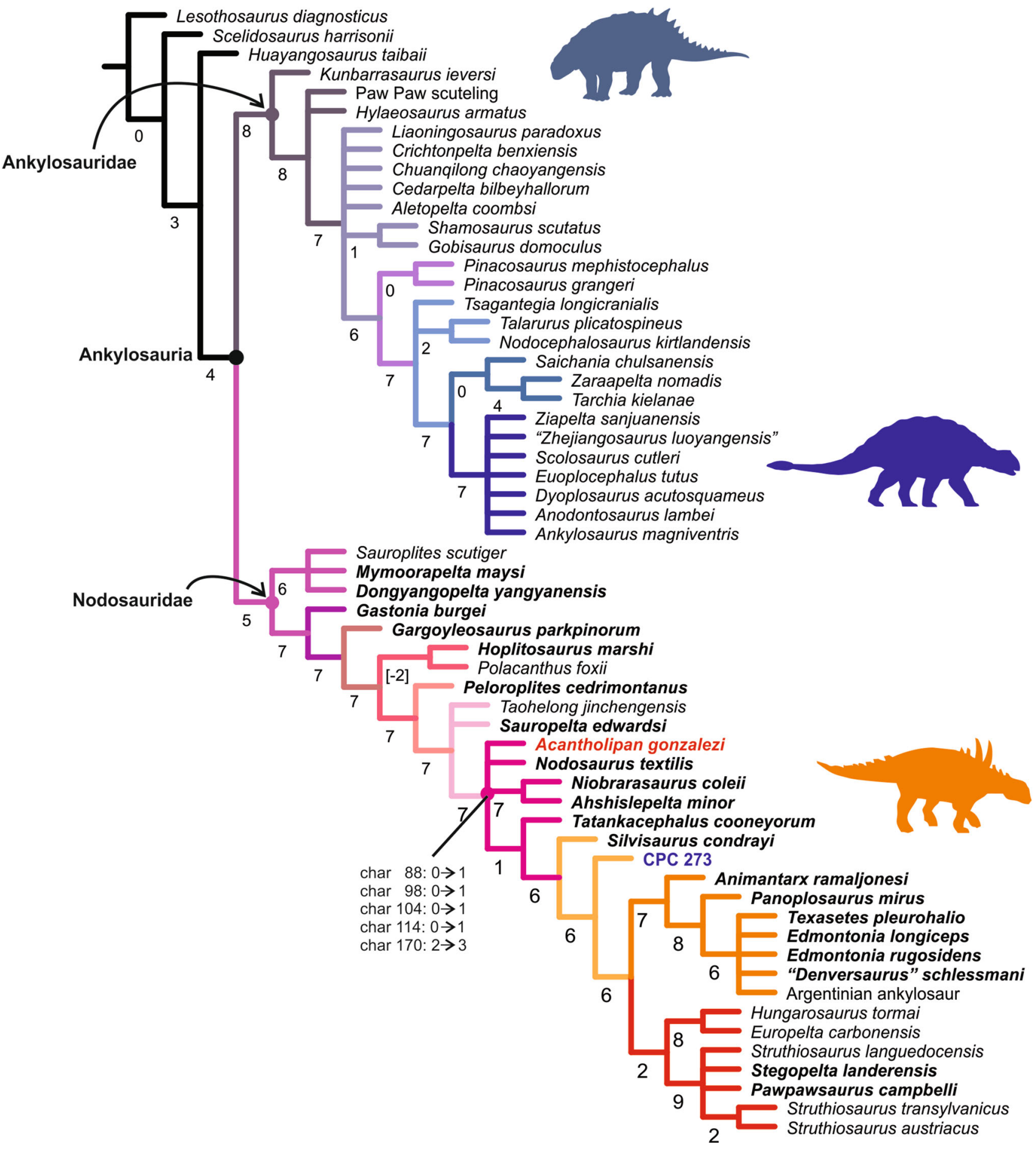

Fig. 5 Strict consensus tree of Ankylosauria, illustrating the phylogenetic position of Acantholipan gonzalezi and CPC 273 (TL: 573, CI: 0.396, RI: 0.648). North American nodosaurids are marked in bold. Numbers below line are Bremer Support

The remains of A. gonzalezi were discovered in coastal to shallow marine sediments, like those of other nodosaurids (e.g., Aletopelta, Borealopelta, Nodosaurus, Stegopelta, Pawpawsaurus, and Niobrarasaurus, Carpenter and Kirkland 1998; Carpenter et al. 1995; Ford and Kirkland 2001; Arbour et al. 2016; Brown et al. 2017).

Nodosauridae indet. 


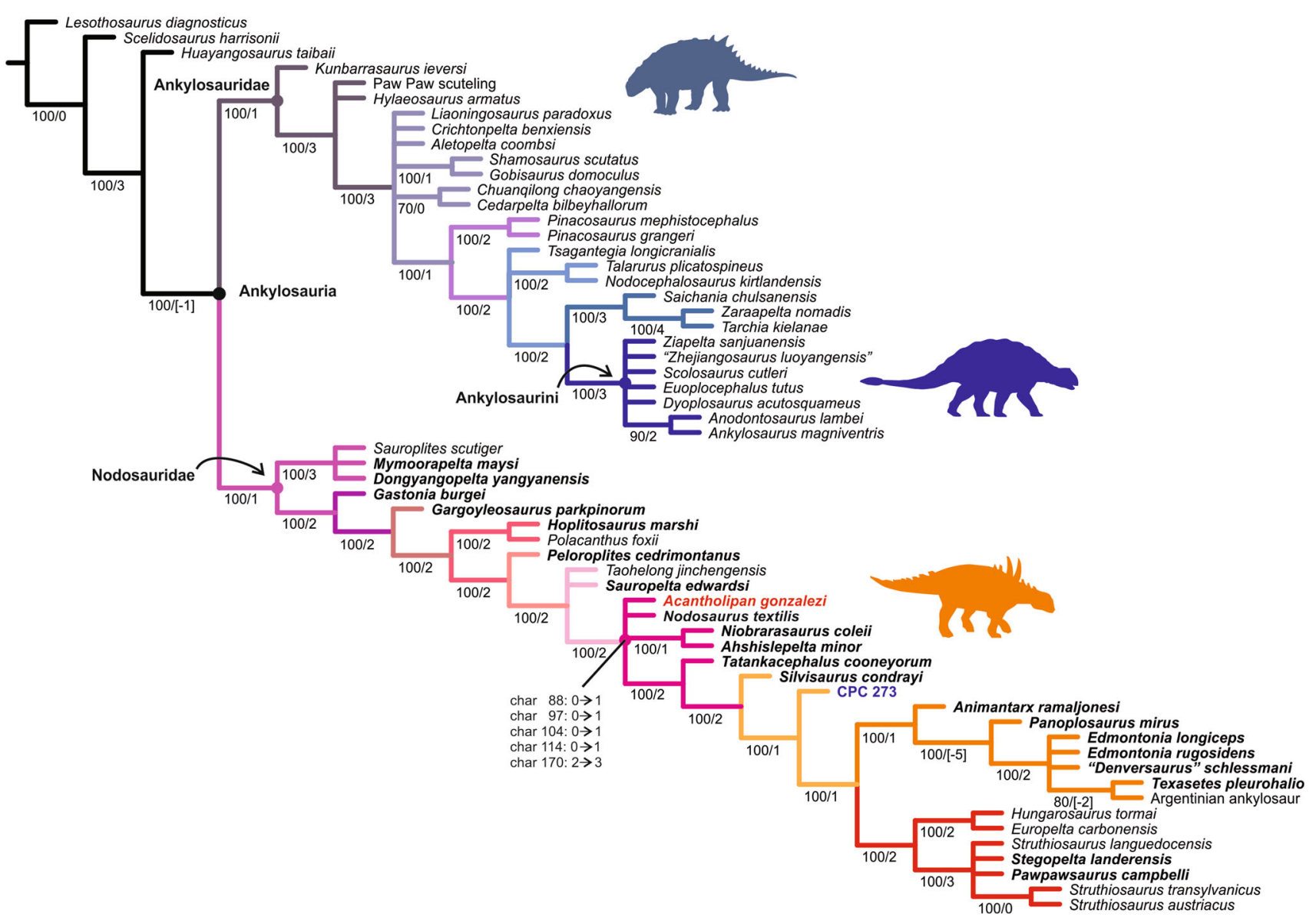

Fig. 6 Majority rule tree (cut 50\%) of Ankylosauria, showing the position of Acantholipan gonzalezi and CPC 273 (TL: 569 , CI: 0.399, RI: 0.652). North American nodosaurids are here marked in bold. Numbers below line frequency/Bremer

Evidence for Nodosauridae comes from the El Jabón Creek locality, "El Gallo Formation" (Campanian), El Disecado member, Baja California, Mexico. This material includes a tooth (UABC FCM 2625) (Rivera-Sylva et al. 2011a), which resembles those of the nodosaurid Aletopelta coombsi from the Campanian of California (Ford and Kirkland 2001; Rivera-Sylva and Carpenter 2014), which is of similar stratigraphic range. Martínez-Díaz and Montellano-Ballesteros (2011) mention a vertebra from the Campanian Aguja Formation at Los Altares, northeast Chihuahua, and four osteoderms from the El Rebaje locality, northern Coahuila, that were originally referred to Panoplosaurus by Martínez-Díaz and Montellano-Ballesteros (2011). However, ankylosaurian vertebrae are only diagnostic at family level (Vickaryous et al. 2004). RiveraSylva et al. (2011a) describe a nodosaurid caudal vertebra from the Cerro del Pueblo Formation, and Martínez-Díaz and Montellano-Ballesteros (2011) mention the presence of nodosaurid osteoderms and a tooth from the same formation, but the "osteodermal spine" in their description was later identified as the nasal horn of a ceratopsian, because the core has a thick cortical layer with a spongious center (Carpenter, pers. comm., 2016).

Rivera-Sylva et al. (2011a: Fig. 4) described Specimen C (CPC 273) as 'Nodosauridae indet.'. In this individual, the external ornamentation of the osteoderm most closely resembles that reported by Burns (2008) for Glyptodontopelta in showing large smooth areas interrupted by a moderate amount of randomly distributed small pits and vascular grooves that radiate from the keel. In contrast to the osteoderms of Glyptodontopelta, the external texture of the CPC 273 is less extensive and shallower.

The basal plates of the thoracic osteoderms of CPC 273 are round (Rivera-Sylva et al. 2011a). The keel is prominent and directed laterally. It emerges from the craniomedial margin and continues in oblique direction caudolaterally; it ends at the caudal margin of the osteoderm. The external surface is ornamented with shallow radiating dendritic grooves. This ornamentation differs from both Panoplosaurus and Glyptodontopelta, which 
lack a dendritic surface on their osteoderms, being rather smooth. According to Rivera-Sylva et al. (2011a), CPC 273 preserves one of the lateral-most osteoderms of the anterior-most cervical ring and one spine that closely resembles those projecting anterolaterally from the neck of Stegopelta (Carpenter and Kirkland 1998). The large oval low-keeled osteoderm of CPC 273 resembles the medial osteoderms of Edmontonia rugosidens (AMNH 5665).

\section{Phylogenetic analysis}

Ten most parsimonious trees were recovered from our phylogenetic analysis with a best score of 555 (TBR). Both strict and majority rule trees are similar in their general topology. The strict consensus tree shows a CI of 0.396, RI of 0.648 and TL of 573 (Fig. 5). The majority rule tree presents a CI of 0.399, RI of 0.652 and TL of 569 (Fig. 6).

Although few characters could be scoring to Acantholipan gonzalezi and CPC 273, they give an idea of the phylogenetic position of the analyzed specimens and the results show that both taxa are nested within Nodosauridae.

In our analysis, Sauroplites scutiger, Mymoorapelta maysi and Dongyangopelta yangyanensis form a polytomy and are considered as the basal-most clade of nodosaurs. Acantholipan gonzalezi is recovered in polytomy comprising Nodosaurus textilis, but also with Ahshislepelta + Niobrarasaurus and a large unnamed clade comprising Tatankacephalus and more nested taxa. Within nodosaurs, CPC 273 is definitely more deeply nested among ankylosaurid OTUs than A. gonzalezi, and is positioned as sister taxon to the clade composed of two lineages, one predominately North American and the second largely being Eurasian in taxic scope. The North American group, which comprises Animantrax, Panoplosaurus, Edmontonia spp., "Denversaurus", Texastes, and the Argentinian ankylosaur, could bear the label Panoplosaurinae. The unnamed second clade contains the Eurasian forms Hungarosaurus, Europelta, and Struthiosaurus, and the North American Stegopelta and Pawpawsaurus. The indeterminate juvenile nodosaurid from the Paw Paw Formation is identified as a basal ankylosaur, contrary to the analysis of Arbour et al. (2016) in which this OTU was interpreted to be a derived nodosaurid close to Ahshislepelta minor and Niobrasaurus coleii.

Our consensus tree by majority rule is slightly different from that obtained by Arbour et al. (2016), mainly in the resolution of Nodosauridae. These differences are less evident when Acantholipan gonzalezi and CPC 273 are included.

\section{Discussion}

The presence of the new nodosaurid from northeastern Mexico, Acantholipan gonzalezi, provides further evidence for an isolated local endemism, which has been similarly reported for other coeval dinosaurs of southern Laramidia (Lehman 1987, 1997, 2001; Sankey 2008; Prieto-Marquez et al. 2012; and Rivera-Sylva et al. (2011b, 2017). On a global scale, ankylosaur diversity appears to be correlated with the diversification of specific food plants (Ösi et al. 2017). In America, this diversification of vegetation may have depended on climate, resulting in a north-south gradient. It was likely characterized by periodic semi-arid to arid intervals occurring earlier in the south than in the north and resulting in a vicariation of vegetation regimes. Ankylosaurs reacted to these climatic and vegetation changes with diversification, resulting in a climatic and floral decoupling of North and South Laramidia and an allopatric separation of species of herbivore dinosaurs such as ankylosaurs (Loewen et al. 2013).

The likely endemism of the two ankylosaurids of northeastern Mexico, Acantholipan gonzalezi and CPC 273 , is consistent to that seen in other coeval dinosaurs from the area (i.e., tyrannosaurids, hadrosaurids, and ceratopsians), which have also been interpreted as endemic to this particular region as a result of the ecological separation of northern and southern Laramidia (Sampson et al. 2004; Sampson and Loewen 2010; Sampson et al. 2010; Gates et al. 2012). A hitherto unknown geographical or climatic barrier may consequently have separated northeastern Mexico and thus the southern shoreline of Laramidia, from areas located to the north of the subcontinent. This barrier must have existed long enough to allow for an allopatric diversification of northern and southern Laramidian faunal regimes (Rivera-Sylva et al. 2011b).

\section{Conclusions}

Here, we present the first diagnosable nodosaurid ankylosaur from Mexico and the southernmost North American thyreophoran: Acantholipan gonzalezi. The phylogenetic analysis of this Santonian taxon supports the inclusion of this new genus and species within Nodosauridae.

Significant faunal differences existed between Late Cretaceous dinosaur assemblages of North and South Laramidia and were likely triggered by climatic belts across the continent resulting in a diversification of floral regimes. This interpretation is consistent with the high degree of endemism of Late Cretaceous dinosaurs in northeastern Mexico, including the one described here. Although the diagnostic material of Mexican Thyreophora 
is presently limited, the discovery of more complete specimens in the future may allow us to better understand the reasons for an allopatric diversification of Thyreophora and other dinosaur groups in the Late Cretaceous of Laramidia.

Acknowledgements We wish to thank the following friends and colleagues for their participation in the project: Lucía Alfaro Ortíz, Fernando Cabral Valdéz, Iván Alexander de León Aguirre (Gosta'n Koh), Héctor Munive Villalobos, Jorge Ortíz Mendieta, and Tatiana Sánchez Rodríguez. We are grateful to the Museo del Desierto in Saltillo, Mexico, and its chairman Arturo González for supporting this investigation. We thank The Willi Hennig Society made TNT freely available. Kenneth Carpenter and Xavier Pereda Suberbiola are acknowledged for their helpful comments on an earlier version of this paper. We thank José Ignacio Ruíz-Omeñaca (MUJA) and Tim Tokaryk (RSM) for their insightful comments on this paper. We want to give special recognition to Jay Nair (UQ) for the time and expertise he devoted to the improvement of this work and for his patience and help at all times, as well as to Daniel Marty, editor of the Swiss Journal of Palaeontology for providing us with editorial assistance when required. The Deutsche Forschungsgemeinschaft (DFG) covered travel and fieldwork expenses for EF (FR1314/19) and WS (STI128/24 and STI128/30). The digital photographs were treated by Volker Griener, Karlsruhe.

\section{References}

Arbour, V. M., \& Currie, P. J. (2016). Systematics, phylogeny and palaeobiogeography of the ankylosaurid dinosaurs. Journal of Systematic Palaeontology, 14(5), 385-444. https://doi.org/10. 1080/14772019.2015.1059985.

Arbour, V. M., Zanno, L. E., \& Gates, T. (2016). Ankylosaurian dinosaur palaeonvironmental implications were influenced by extirpation, sea-level fluctuation, and geodispersal. Palaeogeography, Palaeoclimatology, Palaeoecology, 449, 289-299.

Brown, B. (1908). The Ankylosauridae, a new family of armored dinosaurs from the Upper Cretaceous. Bulletin of the American Museum of Natural History, 24, 187-201.

Brown, C. M., Henderson, D. M., Vinther, J., Fletcher, I., Sistiaga, A., Herrera, J., et al. (2017). An exceptionally preserved threedimensional armored dinosaur reveals insights into coloration and cretaceous predator-prey dynamics. Current Biology, 27, $1-8$.

Burns, M. E. (2008). Taxonomic utility of ankylosaur (Dinosauria, Ornithischia) osteoderms: Glyptodontopelta mimus ForD, 2000. a taste case. Journal of Vertebrate Paleontology, 28(4), $1102-1109$.

Burns, M. E., \& Currie, P. J. (2014). External and internal structure of ankylosaur (Dinosauria, Ornithischia) osteoderms and their systematic relevance. Journal of Vertebrate Paleontology, $34(4), 835-851$.

Carpenter, K. (2004). Redescription of Ankylosaurus magniventris Brown 1908 (Ankylosauridae) from the Upper Cretaceous of the Western Interior of North America. Canadian Journal of Earth Sciences, 41, 961-986.

Carpenter, K. (2012). Ankylosaurs. In J. Farlow \& M. Brett-Surman (Eds.), The complete dinosaur (2nd ed., pp. 505-525). Bloomington: Indiana University Press.

Carpenter, K., Dilkes, D., \& Weishampel, D. B. (1995). The dinosaurs of the Niobrara Chalk Formation (Upper Cretaceous, Kansas). Journal of Vertebrate Paleontology, 15, 275-297.
Carpenter, K., \& Kirkland, J. I., 1998. Review of Lower and Middle Cretaceous Ankylosaurs from North America. In S. G. Lucas, J. I. Kirkland, \& J. W. Estep (Eds.), Lower and Middle Cretaceous Terrestrial Ecosystems. New Mexico Museum of Natural History and Science Bulletin 14 (pp. 249-270).

Coombs, W. P., Jr., \& Deméré, T. A. (1996). A Late Cretaceous nodosaurid Ankylosaur (Dinosauria: Ornithischia) from marine sediments of coastal California. Journal of Paleontology, 70(2), 311-326.

Ford, T., 2000. A review of ankylosaur osteoderms from New Mexico and a preliminary review of ankylosaur armour. In S. G. Lucas, \& A. B. Heckert (Eds.), Dinosaurs of New Mexico: New Mexico Museum of Natural History and Science Bulletin 17 (pp. 157-176).

Ford, T., \& Kirkland, J. I. (2001). Carlsbald ankylosaur (Ornithischia, Ankylosauria): An ankylosaurid and not a nodosaurid. In The Armored (Ed.), Carpenter, K (pp. 239-260). Dinosaurs: Bloomington, Indiana University Press.

Gates, T. A., Prieto-Marquez, A., \& Zanno, L. E. (2012). Mountain building triggered Late Cretaceous North American megaherbivore dinosaur radiaton. PLoS ONE, 7(8), e42135. https://doi.org/ 10.1371/journal.pone.0042135.

Gates, T. A., Sampson, S. D., Delgado de Jesús, C. R., Zanno, L. E., Eberth, D., Hernández, R., et al. (2007). Velafrons coahuilensis, a new lambeosaurine hadrosaurid (Dinosauria: Ornithopoda) from the Late Campanian Cerro del Pueblo Formation, Coahuila, Mexico. Journal of Vertebrate Paleontology, 27(4), 917-930.

Goloboff, P. A., Farris, J. S., \& Nixon, K. C. (2008). TNT, a free program for phylogenetic analysis. Cladistics, 24, 774-786. https://doi.org/10.1111/j.1096-0031.2008.00217.x.

Han, F., Zheng, W., Hu, D., Xu, X., \& Barrett, P. M. (2014). A New Basal Ankylosaurid (Dinosauria: Ornithischia) from the Lower Cretaceous Jiufotang Formation of Liaoning Province, China. PLOS ONE, 9(8), e104551.

Hernández, R. (1997). Mexican dinosaurs. In P. J. Currie \& K. Padian (Eds.), Encyclopedia of dinosaurs (pp. 433-437). San Diego: Academic Press.

Lehman, T. M. (1987). Late Maastrichtian paleoenvironments and dinosaur biogeography in the Western Interior of North America. Palaeogeography, Palaeoclimatology, Palaeoecology, 60, 189-217.

Lehman, T. M. 1997. Late Campanian dinosaur biogeography in the Western Interior of North America. In D. A. Wolberg, \& E. Stump (Eds.), Dinofest International, Proceedings (pp. 223-240). Philadephia: Academy of Natural Sciences.

Lehman, T. M. (2001). Late Cretaceous Dinosaur Provicniality. In D. H. Tanke \& K. Carpenter (Eds.), Mesozoic vertebrate life (pp. 310-328). Bloomington: Indiana University Press.

Loewen, M. A., Burns, M. E., Getty, M. A., Kirkland, J. I., \& Vickaryous, M. K. (2013). Review of Late Cretaceous Ankylosaurian Dinosaurs from the Grand Staircase Region, Southern Utah. In A. L. Titus \& M. A. Loewen (Eds.), At the top of the Grand Staircase: The Late Cretaceous of Southern Utah (pp. 445-462). Bloomington: Indiana University Press.

Maddison, W. P., \& Maddison, D. R. 2018. Mesquite: A modular system for evolutionary analysis. Version $3.40 \mathrm{http} / / /$ mesquite proyect.org.

Marsh, O. C. (1890). Additional characters of the Ceratopsidae, with notice of new Cretaceous dinosaurs. American Journal of Science, Series 3, 39, 81-86.

Martínez-Díaz, J. L., \& Montellano-Ballesteros, M. (2011). Anquilosaurios (Thyreophora-Ankylosauria) del Cretácico Superior de México (p. 93). Puebla: Libro del Resúmenes del XII Congreso Nacional de Paleontología. 
Meyer, C., Frey, E. D., Thüring, B., Etter, W., \& Stinnesbeck, W. (2005). Dinosaur tracks from the Late Cretaceous Sabinas Basin (Mexico). Kaupia, 14, 41-45.

Morris, W. J. (1967). Baja California: Late Cretaceous dinosaurs. Science, 155, 1539-1541.

Morris, W. J. (1981). A new species of hadrosaurian dinosaur from the Upper Cretaceous of Baja California: ?Lambeosaurus laticaudus. Journal of Paleontology, 55(2), 453-462.

Nopcsa, F. (1915). Die Dinosaurier der siebenbürgischen Landesteile Ungarns. Mitteilungen Jahrbuch der Königlich ungarischen geologischen Reichsanstalt, 23, 1-26.

Osborn, H. F. (1923). Two Lower Cretaceous dinosaurs of Mongolia. American Museum Novitates, 95, 1-10.

Ösi, A., \& Pereda-Suberbiola, X. (2017). Notes on the pelvic armor of European ankylosaurs (Dinosauria: Ornithischia). Cretaceous Research. https://doi.org/10.2016/j.cretres.2017.03.2017.

Ősi, A., Prondvai, E., Mallon, J., \& Reka Bodor, E. (2017). Diversity and convergences in the evolution of feeding adaptations in ankylosaurs (Dinosauria: Ornithischia). Historical Biology, 29(4), 539-570.

Owen, R. (1842). Reporto n British fossils reptiles. Part II. Report of the British Association for the Advancement of Science, 1841, 60-204.

Palomino-Sánchez, F. J. 2008. Informe Técnico. Instituto Nacional de Estadística, Geografía e Informática (unpublished technical report).

Prieto-Márquez, A., Chiappe, L. M., \& Joshi, S. H. (2012). The Lambeosaurine Dinosaur Magnapaulia laticaudus from the Late Cretaceous of Baja California, Northwestern Mexico. PLoS ONE, 7(6), e38207. https://doi.org/10.1371/journal.pone.0038207.

Prieto-Márquez, A., \& Serrano Brañas, C. I. (2012). Latirhinus uitstlani, a 'broad-nosed' saurolophine hadrosaurid (Dinosauria, Ornithopoda) from the late Campanian (Cretaceous) of northern Mexico. Historical Biology, 24(6), 607-619.

Ramírez-Velasco, A. A., Benammi, M., Prieto-Márquez, A., Alvarado-Ortega, J., \& Hernández, R. (2012). Huehuecanauhtlus tiquichensis, a new hadrosauroid dinosaur (Ornithischia: Ornithopoda) from the Santonian (Late Cretaceous) of Michoacán, Mexico. Canadian Journal of Earth Sciences, 49(2), 379-395.

Ramírez-Velasco, A. A., \& Hernández, R. (2014). Diversity of Late Cretaceous dinosaurs from Mexico. Boletín Geológico y Minero, 126(1), 63-108.

Ramírez-Velasco, A. A., Hernández, R., \& Servin-Pichardo, R. (2014). The Hadrosaurian record from Mexico. In D. A. Eberth \& D. C. Evans (Eds.), Hadrosaurs (pp. 340-360). Bloomington: Indiana University Press.

Rivera-Sylva, H. E., \& Carpenter, K. (2014). Ornithischian dinosaurs from Mexico. In H. E. Rivera-Sylva, K. Carpenter, \& E. Frey (Eds.), Dinosaurs and other reptiles from the Mesozoic from Mexico (pp. 156-180). Bloomington: Indiana University Press.
Rivera-Sylva, H. E., Carpenter, K., \& Aranda-Manteca, F. J. (2011a). Late Cretaceous Nodosaurids (Ankylosauria: Ornithischia) from Mexico. Revista Mexicana de Ciencias Geológicas, 28(3), 271-278.

Rivera-Sylva, H. E., \& Espinosa-Chávez, B. 2006. Ankylosaurid (Dinosauria: Thyreophora) osteoderms from the Upper Cretaceous Cerro del Pueblo of Coahuila, Mexico. Carnets de Géologie, Brest, Letter 2006/02 (CG2006_L02), 1-5.

Rivera-Sylva, H. E., Frey, E., Guzmán-Gutiérrez, R., PalominoSánchez, F., \& Stinnesbeck, W. (2011b). Deinosuchus riograndensis (Eusuchia: Alligatoroidea) from Coahuila, Mexico. Revista Mexicana de Ciencias Geológicas, 28(2), 267-274.

Rivera-Sylva, H. E., Frey, E., Stinnesbeck, W., Guzmán-Gutiérrez, R., \& González-González, A. H. (2017). Mexican ceratopsids: Considerations on their diversity and biogeography. Journal of South American Earth Sciences, 75, 66-73.

Russell, L. S. 1940. Edmontonia rugosidens (Gilmore) an armoured dinosaur from the Belly River series of Alberta. University of Toronto Studies, Geological Series, no. 4.

Sampson, S. D., \& Loewen, M. A. (2010). Unraveling a radiation: A review of the diversity, stratigraphic distribution, biogeography, and evolution of horned dinosaurs (Ornithischia: Ceratopsidae). In M. J. Ryan, B. ChinneryAllgeier, \& D. A. Eberth (Eds.), New perspectives on horned dinosaurs (pp. 405-427). Bloomington: Indiana University Press.

Sampson, S. D., Loewen, M. A., Farke, A. A., Roberts, E. M., Forster, C. A., Smith, J. A., et al. (2010). New horned dinosaurs from Utah provide evidence for intracontinental dinosaur endemism. PLoS ONE, 5(9), 1-12.

Sampson, S. D., Loewen, M. A., Roberts, E. T., Smith, J. A., Zanno, L. E., \& Gates, T. (2004). Provincialism in Late Cretaceous terrestrial faunas: New evidence from the Campanian Kaiparowits Formation of Utah. Journal of Vertebrate Paleontology, Supplement to, 24, 108A.

Sankey, J. T. (2008). Vertebrate Paleobiology from Microsites, Talley Mountain, Upper Aguja Formation (Late Cretaceous), Big Bend National Park, Texas, USA. In J. T. Sankey \& S. Baszio (Eds.), Vertebrate Microfossils Assemblages (pp. 61-77). Bloomington: Indiana University Press.

Seeley, H. G. (1887). On the classification of the fossil animals commonly called Dinosauria. Proceedings of the Royal Society of London, 43, 165-171.

Sternberg, C. M. (1928). A new armored dinosaur from the Edmonton Formation of Alberta. Transactions of the Royal Society of Canada, 22, 93-104.

Vickaryous, M. K., Maryańska, T., \& Weishampel, D. B. (2004). Ankylosauria. In D. B. Weishampel, P. Dodson, \& H. Osmólska (Eds.), The Dinosauria (pp. 363-392). Berkeley: University of California Press. 